\title{
Difficulties in the Use of Ground Bacterial Cellulose (BC) as Reinforcement of Polylactid Acid (PLA) Using Melt-Mixing and Extrusion Technologies
}

\author{
Katrin Gan $\aleph^{1}$, Axel Nechwatal ${ }^{1}$, Katrin Frankenfeld ${ }^{2}$, Kerstin Schlufter ${ }^{3}$ \\ ${ }^{1}$ Department of Textile and Material Research, Thueringisches Institut fuer Textil und Kunststoff-Forschung e.V., Rudolstadt, \\ Germany; ${ }^{2}$ Department Biotechnology, fzmb GmbH Forschungszentrum für Medizintechnik und Biotechnologie, Bad Langensalza, \\ Germany; ${ }^{3}$ Thueringer Landesamt fuer Lebensmittelsicherheit und Verbraucherschutz (TLLV), Bad Langensalza, Germany. \\ Email: ganss@titk.de
}

Received May $23^{\text {rd }}, 2012$; revised June $20^{\text {th }}, 2012$; accepted July $11^{\text {th }}, 2012$

\begin{abstract}
Bacterial cellulose (BC) was ground to make the material suitable for compounding with polylactid acid (PLA). The content of BC in PLA was changed between 5 and $20 \mathrm{wt} \%$. By increasing the BC content of the composite DSC measurements showed an increase of crystallinity $\left(\chi_{c}\right)$. Annealing at $90^{\circ} \mathrm{C}$ resulted in a further increase of $\chi_{c}$. Analysis of the dynamic mechanical behavior showed a sharp decline of the storage module $\left(G^{\prime}\right)$ above the glass transition temperature $\left(\mathrm{T}_{\mathrm{g}}\right)$ while such a sharp decline did not occur for annealed samples. This indicates that the stiffness of PLA even above $\mathrm{T}_{\mathrm{g}}$ can be improved by $\mathrm{BC}$ and annealing.
\end{abstract}

Keywords: Polymer-Matrix Composite; Extrusion; Bacterial Cellulose

\section{Introduction}

Cellulose is the most abundant material in the world. About 1.5 trillion tons of cellulose grows every year [1-3]. The different sources are wood, straw, cotton or other plant based materials. Cellulose from these sources is widely used in different industries, such as the paper industry, the chemical industry (plastics like cellulose acetate), the textile industry (e.g. viscose fibers) [1] or even in the food industry (to improve texture and reduce energy) [4]. A very interesting field is the use of cellulose fibers to reinforce plastic materials like natural fiber reinforced polypropylene, which has been used in the automotive industry for many years, for example to produce lightweight and stiff door panels [5,6]. Next to plants cellulose can furthermore be microbial synthesized $[1,7]$. In that case the aerobic metabolic process is carried out by bacteria (in our case: Gluconacetobacter xylinum) at the interface between a nutrient medium and air. Bacterial cellulose fibers have dimensions in nanometerscale (diameter $50-250 \mathrm{~nm}$; length of some $\mu \mathrm{m}$ ) and build a fibrous network. Therefore, BC is mostly used in medical applications such as scaffolds or blood vessels or in cosmetic applications [1,8-10]. Its perfect mechanical properties (E-Modul: 15 - $35 \mathrm{GPa}$, tensile strength: 200 $300 \mathrm{MPa}$ ) [1] and high aspect ratio makes BC suitable as reinforcing material. Different academic studies have already pointed out the potential of $\mathrm{BC}$ as a nano-scale and renewable reinforcing material. Using a transparent matrix material, good fiber adhesion and a homogenous dispersion of $\mathrm{BC}$ without agglomeration resulted in an optically transparent composite [11]. In other investigations $\mathrm{BC}$ was used to modify the surface of natural fibers like sisal [12]. Gea et al. tried to produce in-situ poly (vinyl alcohol) composites by adding a PVA solution directly to the growing medium. The addition of PVA to a BC network results in a decrease of the Young's modulus but in an improved transparency [13]. BC in acrylic composites results in an improvement of the storage modulus, but $\mathrm{T}_{\mathrm{g}}$ of the resin was hardly influenced. SEM also showed a strong interfacial adhesion between BC and acrylic resin [14]. BC is mostly used in a so-called "never-dried" state and in some cases also as dissolution to produce a composite. In our research we used dry pieces of $\mathrm{BC}$ and ground them into small particles; those can be added to thermoplastic matrices like PLA during industrial relevant processes like extrusion or compounding.

\section{Materials and Methods}

\subsection{Materials}

$\mathrm{BC}$ in lyophilized form was provided by the Forschungszentrum für Medizintechnik und Biotechnologie $\mathrm{GmbH}$, 
Germany (fzmb). PLA (Ingeo® 3051D from NatureWorks LLC; D-content $=4 \mathrm{wt} \%$ ) was supplied by Resinex, Germany.

\subsection{Biocomposite Preparation}

As a first step, the $\mathrm{BC}$ was ground twice in a cutting mill (SM 100 from Retsch, Germany) with a bottom sieve with trapezoid holes (final size $1.5 \mathrm{~mm}$ ). The milled BC was dried at $105^{\circ} \mathrm{C}$ for two hours before processing.

To provide stable feed and avoid segregation during extrusion PLA was ground under influence of liquid nitrogen. PLA was dried at $50^{\circ} \mathrm{C}$ for four hours before processing.

For preparing compounds of PLA and BC as well as for the neat PLA a Haake PolyLab OS combined with Rheomex OS (Thermo Scientific) with 5 heating zones and a single-orificed nozzle was used.

Neat PLA was also prepared by extrusion at a temperature of $190^{\circ} \mathrm{C}$ for all heating zones and a speed of 50 $\min ^{-1}$ to ensure that all samples have the same thermal history. The melt strand was cooled down in a water bath and finally cut in a pelletizer with a cut length of $1 \mathrm{~mm}$.

For preparing the PLA/BC-compounds both materials were dry pre-mixed in defined ratios, 5, 10 and $20 \mathrm{wt} \%$ respectively, and finally mixed by extrusion like the neat PLA with the same parameters, expect for the compound with $20 \mathrm{wt} \% \mathrm{BC}$ which was compounded at a speed of $40 \mathrm{~min}^{-1}$.

After drying (at $50^{\circ} \mathrm{C}$ till $0.5 \%$ moisture) the granules were pressed between two steel plates at $190^{\circ} \mathrm{C}$ and a pressure of $750 \mathrm{~N} / \mathrm{cm}^{2}$ for two minutes and then cooled for $10 \mathrm{~min}$ at constant pressure. The thickness of the plates was adjusted using a spacing frame with a thickness of $2 \mathrm{~mm}$. The samples are named PLA for neat PLA and PLA/BC X/Y for a PLA composite with Y wt\% BC (e.g. PLA/BC $95 / 5$ for a PLA composite with $5 \mathrm{wt} \%$ $\mathrm{BC}$ ).

For every material version one part was annealed additionally at $90^{\circ} \mathrm{C}$ for two hours in a heating oven. The annealed samples are marked with a $t$ (e.g. PLA/C 95/5t).

\subsection{Bio-Composite Characterization}

\subsubsection{DSC}

Thermal properties $\left(T_{g}, T_{m}, \chi_{c}\right)$ were investigated by differential scanning calorimetry with a DSC 822 from Mettler Toledo, under a nitrogen atmosphere. The first heating was from $20^{\circ} \mathrm{C}$ to $200^{\circ} \mathrm{C}$, after cooling the material was heated in a second step to $350^{\circ} \mathrm{C}$. The heating and cooling rate was $10 \mathrm{~K} / \mathrm{min}$.

The crystallinity of PLA and PLA/BC composites was determined by

$$
\chi_{c}=\frac{\Delta H_{m}-\Delta H_{c}}{\Delta H_{m}^{0} * w} * 100 \%
$$

where $\chi_{c}$ is the crystallinity, $w$ the weight fraction of PLLA in the composite, $\Delta H_{m}$ is the melting enthalpy and $\Delta H_{c}$ is the enthalphy of cold cristallization from DSC measurements and $\Delta H_{m}^{0}$ is the melting enthalpy for $100 \%$ PLLA [15].

\subsubsection{Tensile Tests}

Tensile test were carried out according to DIN EN ISO 527 using a Universal Testing Instrument 4466 from Instron with a $10 \mathrm{kN}$ load cell. For measuring the Emodulus the test speed was $1 \mathrm{~mm} / \mathrm{min}$, elsewise 5 $\mathrm{mm} / \mathrm{min}$. The thickness of the specimen was $2 \pm 0.1 \mathrm{~mm}$, the width $20 \pm 1 \mathrm{~mm}$. The gauge length was $100 \mathrm{~mm}$, while the extensometer length was $50 \mathrm{~mm}$.

\subsubsection{DMTA}

Dynamic-mechanical analysis were carried out with a Dynamic Analyzer RDA II and Orchestrator Software, Rheosource Series II (Rheometric Scientific) using temperature sweep and torque mode. The specimens had a thickness between 2.0 to $2.3 \mathrm{~mm}$ and a width between 10.7 and $11.3 \mathrm{~mm}$. The measuring length was $(25.3 \pm 0.4)$ $\mathrm{mm}$. The dynamic storage and loss moduli were determined at a constant angular frequency of $6.28 \mathrm{rad} / \mathrm{s}$ as a function of temperature from $-50^{\circ} \mathrm{C}$ to $140^{\circ} \mathrm{C}$, a heating rate of $2 \mathrm{~K} / \mathrm{min}$ and a deformation of $0.1 \%$.

\subsubsection{Microscopy}

For microscopic investigations a microscope from ZEISS (Axiotech $100 \mathrm{HD}$ ) with a CCD camera (AVT Horn) was used. Ground BC was separated on a glass slide and examined at a magnification of 2.5 .

For determining the size of the milled $\mathrm{BC}$ the software Axiovision (ZEISS) was used and a minimum of 400 particles were measured. As the ground $\mathrm{BC}$ particles did not show any regular shapes, it is difficult to define its length and width. Thus, we decided to measure the particle surface area to define the particle size.

Scanning electron microscopy (SEM) investigations were performed using a cross beam basis system (Auriga, ZEISS). Prior to SEM the samples were coated with Au.

\section{Results and Discussion}

\subsection{Measuring Particle Size of Ground BC}

There is a broad distribution of particle size of the ground $\mathrm{BC}$ as shown in Figure 1. As already mentioned and as it can be seen in Figure 1, the BC-particels have a complex shape making it difficult to determine length and width. Therefore, the surface area was determined 
also to compare with $\mathrm{BC}$ ground with other sieve size (not shown). The statistical analysis of the particle size results in an arithmetic average of $94,650 \mu \mathrm{m}^{2}$ with a coefficient of variation of $93.2 \%$ that can be seen in the broad distribution. $50 \%$ of the particles have a smaller surface than $71,348 \mu \mathrm{m}^{2}$, but because of the fibrous network and the folding of the particles the effective surface in the composite will be higher.

Surprisingly, there are no fibrils around the particles. The same was seen at SEM investigations (Figure 2). However, the fibrous network, for which BC is wellknown, can be observed at higher magnification, but only on the surface; deeper regions are impervious.

\subsection{Influence of $B C$ and Annealing on Thermal Properties}

The DSC curves show that $\mathrm{BC}$ has an influence on the thermal properties of PLA, especially on its crystallization behavior (Figure 3). For the untreated sample no exothermic peak (cold crystallization) occurred at neat PLA but a significant exothermic peak for the composites PLA/BC 95/5 and PLA/BC 80/20 was noted. The exothermic peak appears at $123.20^{\circ} \mathrm{C}$ for $5 \mathrm{wt} \% \mathrm{BC}$ and at $117.06^{\circ} \mathrm{C}$ for $20 \mathrm{wt} \% \mathrm{BC}$ (see also Table 1). This means, $\mathrm{BC}$ particles act as a nucleating agent as it was also observed by other research groups using microfibrillated cellulose [16]. DSC curves of annealed PLA and PLA/BC composites do not show any exothermic peak. Thus, crystallization might be completed. Furthermore, $\mathrm{BC}$ does not influence significantly the glass transition temperature $\left(\mathrm{T}_{\mathrm{g}}\right)$ or melting temperature $\left(\mathrm{T}_{\mathrm{m}}\right)$ for the not

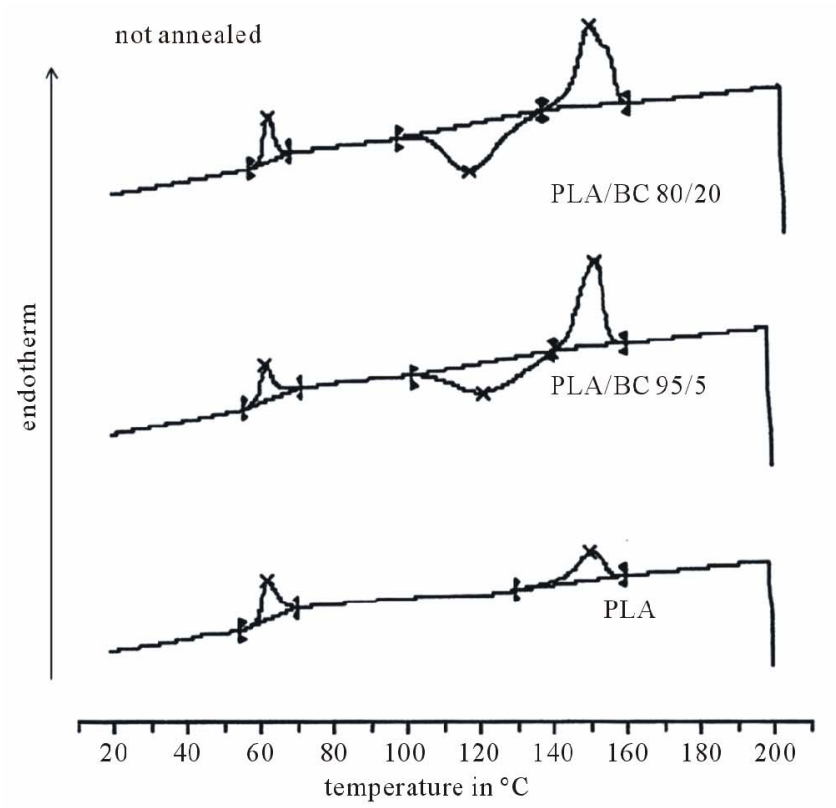

annealed samples. After annealing only neat PLA shows a $T_{g}$. Comparing the $T_{g}$ of untreated and annealed PLA shows an increase of $5 \mathrm{~K}$ for PLA-t. Furthermore the BC

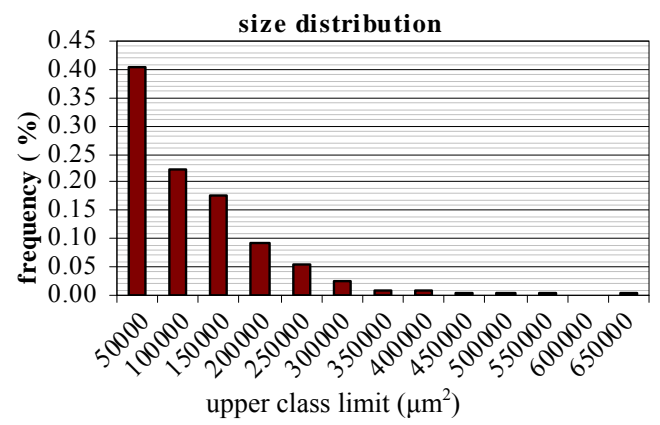

Figure 1. Size distribution of ground BC.

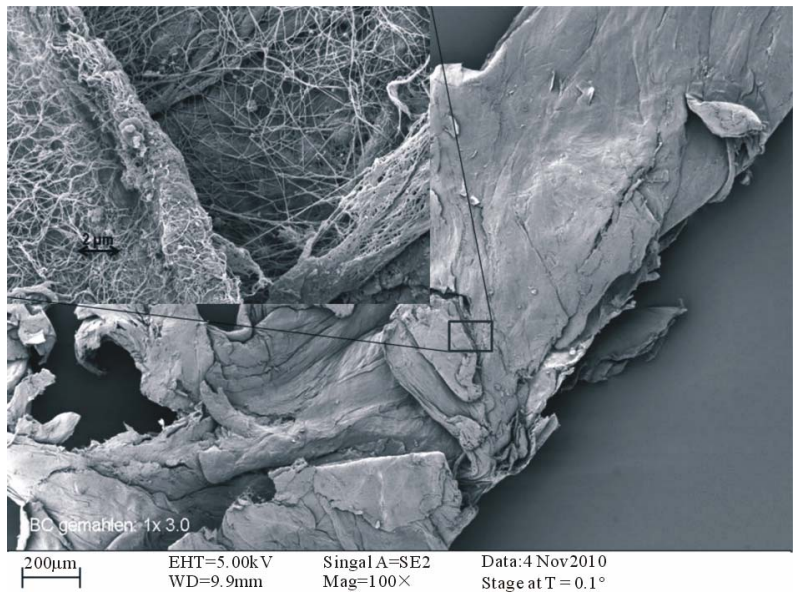

Figure 2. Scanning electron micrographs of ground BC.

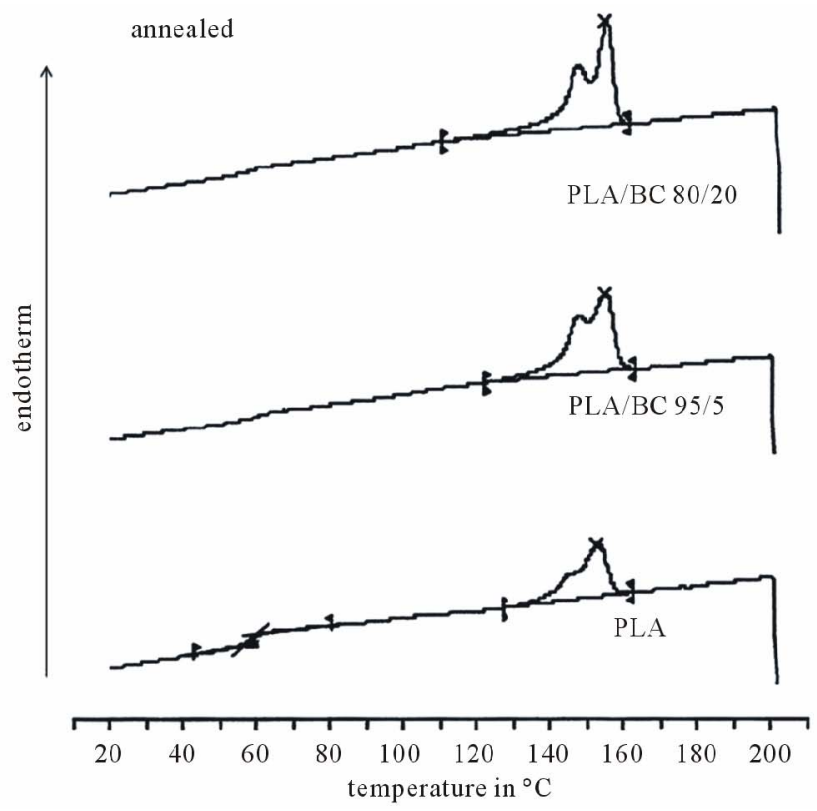

Figure 3. DSC plots of PLA and PLA/BC-composites: left: without annealing; right: with annealing. 
Table 1. Thermal properties of annealed and untreated PLA and PLA/BC composites.

\begin{tabular}{lccccccc}
\hline & \multicolumn{3}{c}{ untreated } & \multicolumn{3}{c}{ annealed } \\
\hline BC-content & ${ }^{\mathrm{wt} \%}$ & 0 & 5 & 20 & 0 & 5 & 20 \\
\hline $\mathrm{T}_{\mathrm{g}}$ & ${ }^{\circ} \mathrm{C}$ & 64.17 & 64.36 & 63.37 & 58.94 & - & - \\
$\mathrm{T}_{\mathrm{m}}$ & ${ }^{\circ} \mathrm{C}$ & 151.24 & 153.2 & 148.9 & 152.1 & 154.2 & 153.7 \\
$\chi_{\mathrm{c}}$ & $\%$ & 8.27 & 0.23 & 0.08 & 19.4 & 34.4 & 42.6 \\
$\mathrm{~T}_{\mathrm{c}}$ & ${ }^{\circ} \mathrm{C}$ & - & 123.20 & 117.06 & - & - & - \\
\hline
\end{tabular}

content influences the crystallinity of PLA. The incorporation of $\mathrm{BC}$ does not increase the crystallinity $\left(\chi_{c}\right)$. Improvements can be reached with heat treatment. Comparing not annealed and annealed samples with the same content of BC shows a significant improvement of $\chi_{c}$ in the annealed samples. This also indicates that BC particles act as a nucleating agent [16].

\subsection{Influence of $B C$ and Annealing on Tensile Properties}

All samples show brittle failure behavior (Figure 4) and the elongation at break $\left(\varepsilon_{\mathrm{B}}\right)$ decreases with increasing BC-content (Table 2). Furthermore, $\varepsilon_{\mathrm{B}}$ of the annealed samples has also a lower value compared to untreated samples. The tests show a decrease of the tensile strength $(\sigma)$ with increasing content of BC for both the untreated and annealed PLA/BC composites. This behavior is also known for natural fiber/polypropylene composites [17,18] and indicates a missing stress transfer between the $\mathrm{BC}$ and the matrix. At low fiber loadings the reinforcement acts more as an imperfection and leads to local stress peaks [18]. Except for PLA/BC 80/20 the tensile strength of untreated and annealed samples is on the same level, while for PLA/BC 80/20-t it is surprisingly significantly lower. As expected, the tensile stiffness (E-Modulus) increases with rising $\mathrm{BC}-$ content. As annealing leads to an increasing crystallinity it also improves the tensile modulus.

As Figure 5 shows the $\mathrm{BC}$ particles are uniformly dispersed in the PLA-matrix. With higher magnification SEM-pictures of the fracture surface show a weak fibermatrix-interface with gaps between the BC-particles and the matrix (Figure 4). Using a suitable coupling agent like maleic anhydride-grafted-PLA may improve the interface and consequently the mechanical strength and stiffness as it was already intensively shown for PP/ natural fiber composites $[19,20]$.

Furthermore because of the contrariness of hydrophilic cellulose and more hydrophobic PLA the small interfibrillar spaces between single BC fibrils are not penetrated with the matrix. Hence, the high aspect ratio of the

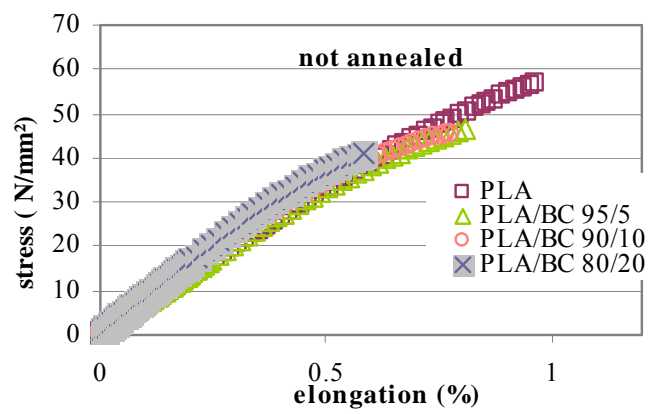

(a)

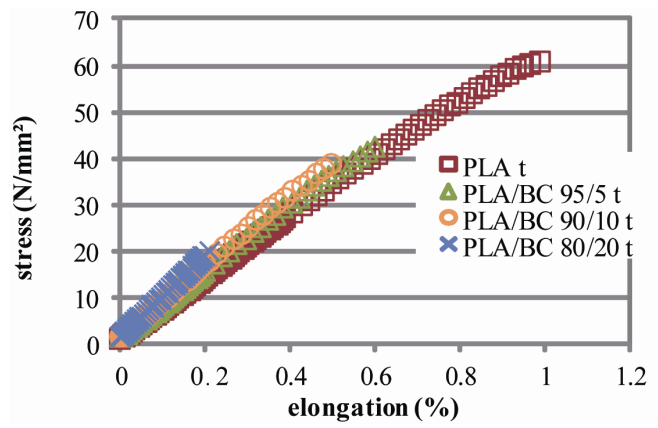

(b)

Figure 4. Stress-strain curves of (a): PLA/BC-composites and (b): annealed PLA/BC-composite.

Table 2. Tensile properties of annealed and untreated PLA and PLA/BC composites.

\begin{tabular}{|c|c|c|c|c|}
\hline & BC-content & $\sigma_{\mathrm{T}}$ & E-modulus & $\varepsilon_{\mathrm{B}}$ \\
\hline & wt $\%$ & $\mathrm{~N} / \mathrm{mm}^{2}$ & $\mathrm{~N} / \mathrm{mm}^{2}$ & $\%$ \\
\hline \multirow{4}{*}{ 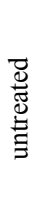 } & 0 & $56.49 \pm 5.15$ & $3337 \pm 45$ & $0.97 \pm 0.29$ \\
\hline & 5 & $44.34 \pm 4.75$ & $3510 \pm 61$ & $0.80 \pm 0.28$ \\
\hline & 10 & $44.77 \pm 1.16$ & $3662 \pm 56$ & $0.78 \pm 0.09$ \\
\hline & 20 & $41.16 \pm 1.74$ & $4185 \pm 152$ & $0.58 \pm 0.12$ \\
\hline \multirow{4}{*}{ 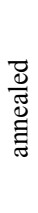 } & 0 & $59.84 \pm 5.31$ & $3529 \pm 329$ & $0.99 \pm 0.27$ \\
\hline & 5 & $45.29 \pm 2.31$ & $3756 \pm 355$ & $0.60 \pm 0.06$ \\
\hline & 10 & $43.15 \pm 2.58$ & $4255 \pm 237$ & $0.49 \pm 0.04$ \\
\hline & 20 & $25.04 \pm 5.08$ & $4409 \pm 251$ & $0.21 \pm 0.11$ \\
\hline
\end{tabular}

BC fibrils is not exploited. Only the surface of the BC particles interacts with the matrix. This leads to low mechanical improvements compared to other natural fiber composites or composites with nano-sized reinforcement.

\subsection{Influence of BC and Annealing on Dynamic Mechanical Properties}

Figure 6 shows that the incorporation of $\mathrm{BC}$ leads to a slight increase of the storage modulus ( $\left.G^{\prime}\right)$. For annealed 


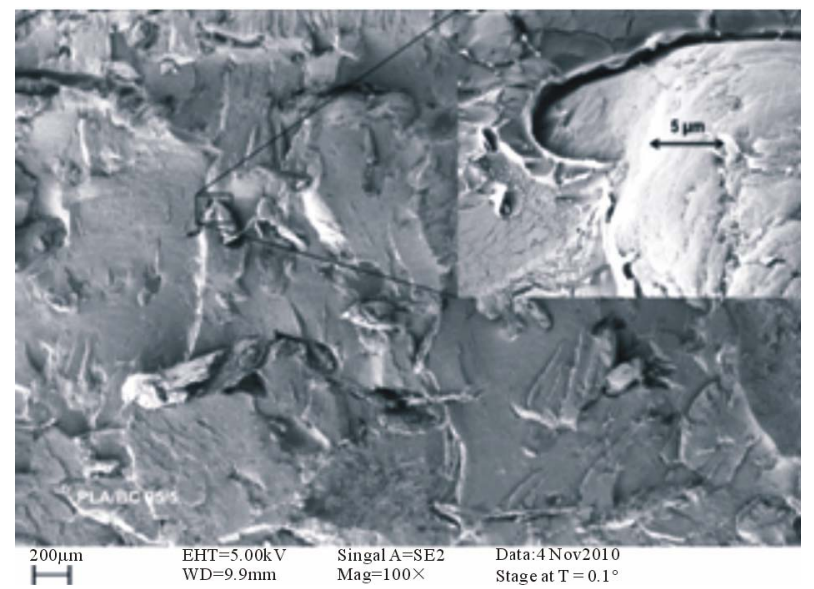

Figure 5. Scanning electron micrographs of the fracture surface of PLA/BC 95/5.

composites $\mathrm{G}^{\prime}$ is higher for all $\mathrm{BC}$ loadings than for neat PLA, a BC content of 5 or $10 \mathrm{wt} \%$ leads to a lower G' in untreated composites. Only the composite with $20 \mathrm{wt} \%$ has a higher G' than PLA, however with annealed PLA all composites show an improved G'.

When comparing untreated and annealed materials the significant difference in the curve progression above $60^{\circ} \mathrm{C}$ (above $\mathrm{T}_{\mathrm{g}}$ ) attracts attention. While for untreated samples a sharp decline of $G^{\prime}$ occurs above $T_{g}$ this decrease is softer for annealed samples. Here the influence of the BC content can be clearly seen. For neat PLA-t the decrease of $G^{\prime}$ is sharper than for the annealed PLA/BC

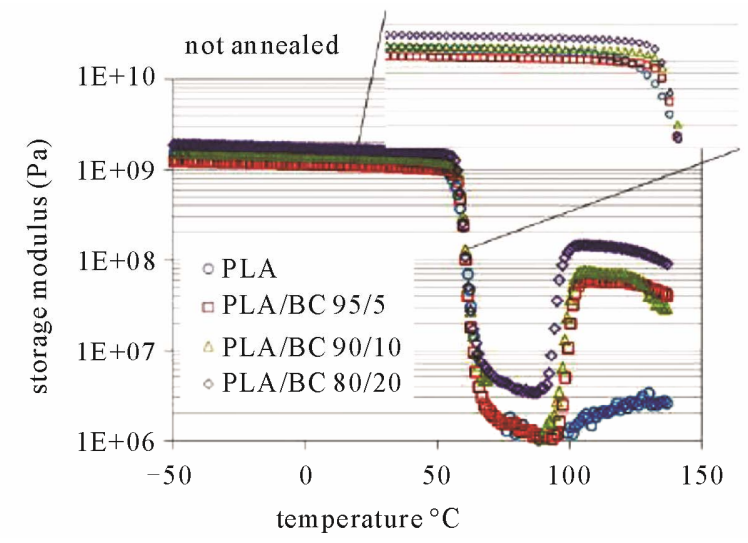

composites. A further increase of temperature leads to a decline of $G^{\prime}$ and at the melting temperature of PLA to a drop in G'. An increasing BC content results in higher G' at elevated temperatures.

The recovery of G' for untreated PLA materials may occur due to cold crystallization as also observed by Pluta and colleagues [21].

The glass transition temperature of all or partly amorphous polymers induces a change from a glassy to a rubber like state. $\mathrm{T}_{\mathrm{g}}$ of PLA was here determined as $\alpha$-relaxation which is indicated by a maximum in loss modulus (G") measurements. This maximum of G" was detected for all samples (Table 3) even for those materials which did not show a $\mathrm{T}_{\mathrm{g}}$ at DSC measurements. Furthermore, annealing as well as the $\mathrm{BC}$ content hardly influence the $\mathrm{T}_{\mathrm{g}}$. That means, $\mathrm{BC}$ does not interact with the molecular chains of the PLA. This indicates the lack of good adhesion between the BC and PLA. Of course, there are differences in the value of $\mathrm{T}_{\mathrm{g}}$ determined by DMTA measurements and measured by DSC which are justified by the differences of the measurements [22].

\section{Conclusion}

DSC measurements showed that both adding $\mathrm{BC}$ and annealing increases $\chi_{c}$ of PLA and melt-mixed PLA/ BC-composites. For annealed composites the fiber loadings resulted in further increase of crystallinity. This also increased the tensile stiffness while tensile strength de-

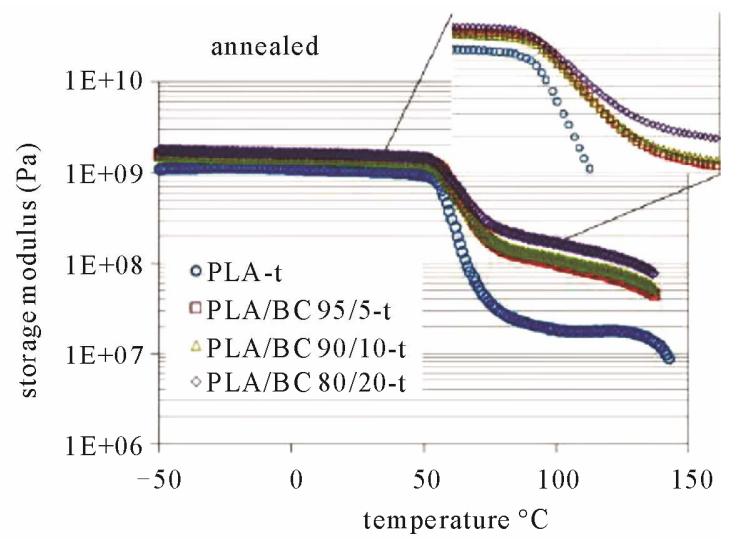

Figure 6. Storage modulus of PLA/BC-composites (left) and annealed PLA/BC-composites (right).

Table 3. $T_{g}$ of PLA determined by local maximum of loss modulus G’’.

\begin{tabular}{|c|c|c|c|c|c|c|c|c|c|}
\hline \multirow[b]{2}{*}{ BC-content } & \multirow[b]{2}{*}{$\mathrm{wt} \%$} & \multicolumn{4}{|c|}{ untreated } & \multicolumn{4}{|c|}{ annealed } \\
\hline & & 0 & 5 & 10 & 20 & 0 & 5 & 10 & 20 \\
\hline $\tan \delta$ & & 3.377 & 2.857 & 2.624 & 2.090 & 0.509 & 0.263 & 0.246 & 0.212 \\
\hline $\mathrm{T}_{\mathrm{g}}$ & ${ }^{\circ} \mathrm{C}$ & 64.68 & 64.64 & 63.74 & 63.61 & 64.61 & 66.66 & 67.72 & 65.63 \\
\hline
\end{tabular}


creases with rising $\mathrm{BC}$-content and did not increase after annealing. This was seen as an indication for less interfacial bonding between the $\mathrm{BC}$ and the PLA-matrix. DMTA measurements showed that the storage modulus G' of untreated PLA and PLA/BC-composites sharply declines around the glass transition temperature of PLA. At approximately $90^{\circ} \mathrm{C}$ G' suddenly increased which might be a result of crystallization. For annealed PLA and PLA/BC-composites the sharp decline at $\mathrm{T}_{\mathrm{g}}$ and the increase at $90^{\circ} \mathrm{C}$ was not observed. Starting at $\mathrm{T}_{\mathrm{g}}$ a rapid reduction of $\mathrm{G}^{\prime}$ of a magnitude for PLA/BC-composites and of two magnitudes for neat PLA did occur. Unfortunately this method (grinding of $\mathrm{BC}$ und melt-mixing via extrusion) is not suitable to achieve significant reinforcements. Even more that $\mathrm{BC}$ consist of nanofibers there must be a clearly better improvement of composite strength and stiffness. From our point of view the interfibrillar space is too small to enable a penetration of the interfibrillar space of the hydrophilic BC with the hydrophobic matrix. Missing linking between the fiber and the matrix make this even more difficult. Thus, improvements of the interfacial bonding between the cellulose fibrils of $\mathrm{BC}$ and the PLA or changes in the $\mathrm{BC}$ network (broader interfibrillar space) must be done to facilitate the use of $\mathrm{BC}$ as reinforcement by melt mixing and extrusion.

\section{Acknowledgements}

The investigations were supported by the Thueringer Aufbaubank and the Free State of Thuringia for financial support from government grant and European Regional Development Fund (ERDF) (project number: 2009 FE 9020). We are grateful for financial support by the institutions carrying project responsibility.

\section{REFERENCES}

[1] D. Klemm, B. Heublein, H. P. Fink and A. Bohn, "Cellulose: Faszinierendes Biopolymer Und Nachhaltiger Rohstoff," Angewandte Chemie, Vol. 107, No. 22, 2005, pp. 3422-3458. doi:10.1002/ange.200460587

[2] R. Kumar, S. Singh and O. V. Singh, "Bioconversion of Lignocellulosic Biomass: Biochemical and Molecular Perspectives," Journal of Industrial Microbiology and Biotechnology, Vol. 35, No. 5, 2008, pp. 377-391.

[3] J. Kim and S. Yun, "Discovery of Cellulose as Smart Material," Macromolecules, Vol. 39, No. 12, 2006, pp. 42024206. doi:10.1021/ma060261e

[4] N. Bilgicli, S. Ibanogli and E. N. Herken, "Effect of Dietary Fibre Addtion on the Selected Nutritional Properties of Cookies," Journal of Food Engineering, Vol. 78, No. 1, 2007, pp. 86-89.

[5] S. Richter, N. Eikelenberg, M. Magnani and J. Müssig, "Sisal as a Reinforcing Agent," Kunststoffe International,
No. 6, 2010, pp. 50-53.

[6] M. Magnani, "Renewable Materials in Ford Motor Company's Vehicles," Proceedings of 8th Global WPC and Natural Fibre Composites Congress and Exhibition, Stuttgart, 22-23 June 2010, pp. B8-1-B8-11.

[7] U. Geyer, T. Heinze, A. Stein, D. Klemm, D. Schumann and H. P. Schmauder, "Formation, Derivatization and Applications of Bacterial Cellulose," International Journal of Biological Macromolecules, Vol. 16, No. 6, 1994, pp. 343-347. doi:10.1016/0141-8130(94)90067-1

[8] A. Svensson, E. Nicklasson, T. Harrah, B. Panilaitis, D. L. Kaplan, M. Brittberg and P. Gatenholm, "Bacterial Cellulose as a Potential Scaffold for Tissue Engineering of Cartilage," Biomaterials, Vol. 26. No. 4, 2005, pp. 419431. doi:10.1016/j.biomaterials.2004.02.049

[9] D. Klemm, D. Schumann, U. Udhardt and S. Marsch, "Bacterial Synthesized Cellulose-Artificial Blood Vessels for Microsurgery," Progress in Polymer Science, Vol. 26, No. 9, 2006, pp. 1561-1603. doi:10.1016/S0079-6700(01)00021-1

[10] H. P. Schmauder, M. Ludwig, K. Frankenfeld, M. Hornung and A. Mülverstedt, "Bakteriencellulose-Ein Interessantes Biomaterial," BioForum, Vol. 23, No. 7, 2000, pp. 484-486.

[11] S. Ifuku, M. Nogi, K. Abe, K. Handa, F. Nakatsubo and H. Yano, "Surface Modification of Bacterial Cellulose Nanofibers for Property Enhancement of Optically Transparent Composites: Depence on Acetyl-Group DS," Biomacromolecules, Vol. 8, No. 6, 2007, pp. 1973-1978. doi:10.1021/bm070113b

[12] A. Delille, A. Mantalaris and A. Bismarck, "Influence of Properties of the Bacterial Cellulose Coating on Natural Fiber Composites," Proceedings of 8th Global WPC and Natural Fibre Composites Congress and Exhibition, Stuttgart, 22-23 June 2010, pp. A20-1-A20-5.

[13] S. Gea, E. Bilotti, C. T. Reynolds, N. Soykeabkeaw and T. Peijs, "Bacterial Cellulose-Poly(Vinyl Alcohol) Nancomposites Prepared by an In-Situ Process," Material Letters, Vol. 64, No. 8, 2010, pp. 901-904.

[14] E. Trovatti, L. Olivera, C. S. R. Freire, A. J. D. Silvestre, C. P. Neto, J. J. C. Cruz and A. Gandini, "Novel Bacterial Cellulose Acrylic Resin Nanocomposites," Composite Science and Technology, Vol. 70, No. 7, 2010, pp. 11481153. doi:10.1016/j.compscitech.2010.02.031

[15] K. Y. Lee, J. J. Blaker and A. Bismarck, "Surface Functionalisation of Bacterial Cellulose as the Route to produce Green Polylactide Nanocomposites with Improved Properties," Composite Science and Technology, Vol. 69, No. 15-16, 2009, pp. 2327-2333.

doi:10.1016/j.compscitech.2009.08.016

[16] L. Suryanegara, A. N. Nakagaito and H. Yano, "The Effect of Crystallization of PLA on the Thermal and Mechanical Properties of Microfibrillated Cellulose-Reinforced PLA Composites," Composite Science and Technology, Vol. 69, No. 7-8, 2009, pp. 1187-1192. doi:10.1016/j.compscitech.2009.02.022

[17] R. A. Sanadi, D. F. Caulfield, R. E. Jacobson and R. M. Rowell, "Renewable Agricultural Fibers as Reinforcing 
Fillers in Plastics: Mechanical Properties of Kenaf FiberPolypropylene Composites," Industrial and Engineering Chemistry Research, Vol. 34, No. 5, 1995, pp. 1889-1896. doi:10.1021/ie00044a041

[18] P.V. Joseph, K. Josepha and S. Thomas, "Effect of Processing Variables on the Mechanical Properties of SisalFiber-Reinforced Polypropylene Composites," Composite Science and Technology, Vol. 59, No. 11, 1999, pp. 16251640. doi:10.1016/S0266-3538(99)00024-X

[19] P. Mutjé, M. E. Vallejos, J. Gironè, F. Vilaseca, A. López, J. A. López and J. A. Mèndes, "Effect of Maleated Polypropylene as Coupling Agent for Polypropylene Composites Reinforced with Hemp Strands," Journal of Applied Polymer Science, Vol. 102, No. 1, 2006, pp. 833-840. doi:10.1002/app.24315

[20] A. Nechwatal, T. Reußmann, S. Böhm and E. Richter,
"The Dependence between the Process Technologies and the Effect of MAH-PP-Adhesives in Natural Fibre Reinforced Thermoplastic Composites," Advanced Engineering Materials, Vol. 7, No. 1-2, 2005, pp. 68-73. doi:10.1002/adem.200400138

[21] M. Pluta, J. K. Jeszka and G. Boiteux, "Polylactide/ Montmorillonite Nanocomposites: Structure, Dielectric, Viscoelastic and Thermal Properties," European Polymer Journal, Vol. 43, No. 7, 2007, pp. 2819-2835. doi:10.1016/j.eurpolymj.2007.04.009

[22] J. Rieger, "The Glass Transition Temperature $\mathrm{T}_{\mathrm{g}}$ of Polymers - Comparison of the Values from Differential Thermal Analyses (DTA, DSC) and Dynamic Mechanical Measurments (Torsion Pendulum)," Polymer Testing, Vol. 20, No. 2, 2001, pp. 199-204. doi:10.1016/S0142-9418(00)00023-4 